\title{
El problema de la violencia en el distrito de Coalcomán, Michoacán (ca. 1940-1980)
}

\section{The Problem of Violence in the District of Coalcoman, Michoacan (ca.1940-1980)}

\author{
Enrique Guerra Manzo \\ (D) 0000-0003-1705-6855 \\ Universidad Autónoma Metropolitana-unidad Xochimilco, México \\ enriqueguerra311@gmail.com
}

Resumen: Este artículo analiza varios tipos de violencia que asolaron al distrito de Coalcomán, Michoacán, ca. 1940-1980, originados en motivos agrarios, diversas formas de delincuencia, siembra de enervantes (violencia instrumental), pistolerismo y vendettas (violencia ritual). Se argumenta que si bien el Estado se esforzó por eliminar a todas ellas, halló mayores dificultades para combatir el pistolerismo y las vendettas. Ello fue así porque la violencia ritual está más arraigada en el habitus de las personas y requería no sólo del desarme de la población (medida a la que más se apostó) sino también de una vigorosa campaña para reformular el habitus y civilizar las pasiones, tarea que un Estado con fuertes debilidades infraestructurales se mostraba incapaz de asumir. Para dar cuenta de lo anterior, el artículo se apoya ante todo en fuentes de primera mano, y en una conceptualización acotada de la violencia, que distingue entre violencia instrumental y violencia ritual.

Palabras clave: violencia; delincuencia; distrito de Coalcomán; Michoacán; Estado mexicano.

Abstract: This article analyzes several types of violence that devastated the District of Coalcomán, Michoacán, ca. 1940-1980, as a result of agrarian issues, various forms of delinquency, the planting of drugs (instrumental vio- 
lence), pistolerismo (hiring thugs to deal with syndicalists) and vendettas (ritual violence). It is argued that, although the state strove to eliminate all of them, it found it hardest to combat pistolerismo and vendettas. This was so because ritual violence is more deeply rooted in people's habitus and required not only disarming the population (the measure that was most often chosen) but also a vigorous campaign to reformulate the habitus and civilize passions, a task that a state with acute infrastructural weaknesses was unable to assume. In order to describe the above, the article relies primarily on first-hand sources, and a limited conceptualization of violence, which distinguishes between instrumental and ritual violence.

Key words: violence; delinquency; district of Coalcoman; Michoacan; Mexican state.

Fecha de recepción: 20 de julio de 2016 Fecha de aceptación: 5 de abril de 2017

E presente artículo centra su atención en una serie de oleadas de violencia $^{1}$ que convergieron entre sí entre 1940 y 1980, en el distrito de Coalcomán, Michoacán: problemas agrarios, delincuenciales (secuestros, robos a casa-habitación, abigeo), siembra de enervantes, pistolerismo e incesantes vendettas (juegos de honor). Las primeras tres oleadas podríamos denominar-

${ }^{1}$ La lucha de definiciones en torno al fenómeno de la violencia no tiene visos de concluir. Algunos autores sugieren que más que hablar de un concepto unificado de violencia, debemos hablar de las violencias y precisar sus tipologías, de acuerdo con lo que nos interese investigar. En lo que concierne a la sociología, los clásicos de esta disciplina no pasaron por alto este fenómeno. En los albores de la modernidad la violencia -"entendida como la acción corporal de cualquier tipo que busca ocasionar un daño físico con el fin de resolver un conflicto"- se caracterizaba por estar muy vinculada al campo político. Hoy, pese a la diversidad de las teorías sociológicas contemporáneas, pueden agruparse en tres grandes tendencias: las que mantienen un enfoque individualista o que priorizan el nivel micro; las de corte estructuralista y las culturalistas, que se centran en el nivel macrosociológico. Pero escaparía a los límites del presente ensayo extenderse en esta discusión. En lugar de ello, opté por precisar las tipologías de la violencia que me interesa investigar. No obstante, aquí se entiende por violencia cualquier intrusión intencional sobre la integridad física de una persona o sobre sus bienes. Para esta definición acotada y sus usos heurísticos, véase Aróstegui (1994, p. 19), Muchembled (2010, p. 10) y Spierenburg (2008, p. 92). Para algunos balances sobre el debate actual en torno al concepto de violencia, véanse Arteaga (2003), Collins (2009), Crettiez (2009), Guerra (2013) y Guzmán (1990). 
las violencia instrumental, en la medida que están avocadas a obtener una ganancia y responden a determinados cálculos racionales, mientras que las dos últimas son más de tipo ritual, pues están más dominadas por la pasión y las emociones que por una fría racionalidad. Empero, todas las clases de violencia tienden a una hibridez y obedecen a mezclas diversas de racionalidad y emociones, es sólo para tipificar sus diferencias que unas podemos verlas más inclinadas hacia un polo $\mathrm{u}$ otro. ${ }^{2}$

La violencia en el distrito de Coalcomán tiene raíces profundas, algunas de las cuales se remontan al siglo XIX (o incluso más allá): una debilidad infraestructural del Estado para penetrar en términos hegemónicos en la región y garantizar el derecho a la seguridad pública; ${ }^{3}$ rivalidades entre pueblos indígenas por linderos de tierras (Figueroa, 2008; Gledhill, 2004; González, 1966; Marín, 2007; Monroy, 2006); invasiones de propiedades comunales por rancheros mestizos que arribaron a la región en diferentes oleadas migratorias; ${ }^{4}$ un elevado grado de aislamiento de la zona ${ }^{5}$ que, aunado a la debilidad

${ }^{2}$ Spierenburg (2008, pp. 196-202) considera que las formas de violencia física pueden ser situadas analíticamente en un intervalo conformado por dos polos, el instrumental y el ritual. La violencia instrumental tiene un carácter más planeado y su objetivo es obtener una determinada ganancia; la violencia ritual concierne a los habitus del perpetrador y está más ligada a las emociones, a una determinada función social y sus respectivas pautas culturales. No obstante, ambas formas de violencia deben verse como puntos extremos de un intervalo en el que hay diferentes gradaciones y mezclas entre lo instrumental y lo ritual, pues por más que la mayoría de los diferentes tipos de violencia tengan un carácter ritual, también son llevados a cabo con miras a un interés particular (por ejemplo, un duelo puede perseguir una venganza que reestablezca el honor mancillado). A su vez, la violencia con una alta naturaleza instrumental es empleada para obtener no sólo una ganancia, sino también algo más (el robo es el clásico ejemplo aquí, pues históricamente los bandidos también tienen sus rituales). Por tanto, la conducta humana violenta siempre cae entre ambos extremos de los dos polos, pero no necesariamente en un punto medio. En principio cada incidente violento puede ser situado en un punto del intervalo. También véase Collins (2009) y Muchembled (2010).

${ }^{3}$ Intentando resumir la evolución de la sociedad en la zona desde el siglo xviII hasta la primera mitad del xx, Cochet (1991, p. 145) señala: "El surgimiento y el desarrollo de esta nueva sociedad agraria se dieron al margen de cualquier estado de derecho y gracias al recurso sistemático a la violencia. Tras las matanzas perpetradas contra la comunidad indígena de Coalcomán [en el siglo XIX] vino una violencia más difusa y esporádica, pero no menos constante".

${ }^{4}$ La primera de ellas en el siglo xviII, la segunda a fines del xix y la tercera entre 1900 y 1920. Cochet (1991, pp. 37-67) y Meyer (1993).

${ }^{5}$ El aislamiento y los caminos difíciles de transitar hasta la primera mitad del siglo $\mathrm{xx}$ propiciaron que en diferentes momentos haya sido lugar de refugio para diversos tipos de gente: tras la Independencia en 1821, para personas que abandonaban los campos de batalla en las regiones más pobladas del norte y este; para una gama de criminales y bandas republi-

\section{(1) (1)}


de las instituciones, propició la emergencia de un habitus violento para resolver cualquier clase de disputas. El estallido de la revolución de 1910 trajo otros trastornos. Primero, auge del bandolerismo, pistolerismo y mayor inseguridad (Ochoa, 1990). Luego, el estallido de la Cristiada (1926-1929) ${ }^{6}$ provocó enfrentamientos entre grupos de rebeldes y Defensas Rurales; en la década de 1930, la reforma agraria suscitó más conflictos, algunos de los cuales desbordaron a las instituciones. Sin embargo, sólo en el periodo ca. 19401980 se puede apreciar el entrelazamiento de esas viejas formas de violencia con otras nuevas, como las provocadas por el cultivo y trasiego de enervantes.

Mi argumento es que las diferentes formas de violencia lastimaron seriamente a la sociedad michoacana del distrito de Coalcomán (en sus vidas y sus bienes) y rebasaron a las autoridades municipales. Los gobiernos estatal y federal si bien se empeñaron en encauzar institucionalmente la conflictividad social en la región y en abatir el flagelo de la violencia, sus esfuerzos fueron insuficientes. Lo cual es un claro indicador de la debilidad infraestructural del Estado. ${ }^{7}$ De esta manera, hasta bien entrada la década de 1980, las interacciones sociales en el distrito estuvieron marcadas en gran medida por la violencia.

\section{LA VIOLENCIA AGRARIA}

El distrito político-electoral de Coalcomán comprende porciones de la región serrana y gran parte de la costa michoacana. ${ }^{8}$ La costa es accidentada y de muy difícil acceso, en la década de 1950 poca gente se internaba en ella. ${ }^{9}$

canas que hacían frente a los franceses e imperialistas que ocuparon la entidad. Anda (1977, pp. 173-174), Arreola (1980), Brand (1958 y 2013), Meyer (1993) y Sánchez y Carreño (1979).

${ }^{6}$ De hecho, el distrito de Coalcomán se convirtió en el principal foco cristero del país. Guerra (2015a, pp. 139-155) y Meyer (1993, vol. III, pp. 155-157).

7 Al respecto, véase Mann (2004).

${ }^{8}$ En el periodo analizado aquí, además de Coalcomán, que fungía como cabecera del distrito, los otros municipios que lo conformaban eran Aquila, Chinicuila, Coahuayana y Aguililla.

${ }^{9}$ Un viajero que recorrió la región en esos años señalaba que a causa de la casi total autosuficiencia de la gente en gran parte de la costa y sierra, a lo espinoso e intrincado de su vegetación, a causa del terreno tan abrupto desde el mar turbulento hasta las montañas que se alzan hacia el cielo, "a causa de todas esas razones y muchas más", hay pocos caminos y pocos viajeros sobre los mismos. Se recorre la región en avión "en una hora o un poco más, o, en lancha, en un día o un poco más, lo que puede tomar de otra manera, muchos días de

\section{()(1) $(9$}


En lo que concierne a la cuestión agraria, a fines del siglo XIX y principios del xx hubo una oleada de despojo de tierras comunales por mestizos en el suroeste michoacano, ${ }^{10}$ cuya base inicial de expansión fue el municipio de Coalcomán (Cochet, 1991; Figueroa, 2008; Gledhill, 2004; González, 1966; Marín, 2007; Monroy, 2006). En las décadas de 1950-1960, con la apertura de carreteras y la cruzada nacionalista impulsadas por las comisiones de la cuenca de Tepalcatepec y luego por la del río Balsas, ${ }^{11}$ el flujo de población a la zona aumentó y con ello las presiones para despojar a los indígenas de las extensas tierras comunales, especialmente las ubicadas en el municipio de Aquila (que abarca a la mayor parte de la costa michoacana). En un principio, algunas comunidades estuvieron dispuestas a rentar parte de sus tierras a los recién llegados y firmaron pactos de protección con algunos hombres fuertes para que les ayudaran a cobrar rentas y a la vez proteger sus amplios territorios. En ello es bastante ilustrativo el caso de la comunidad de Pómaro

ardua y dolorosa labor a pie o a lomos de bestia" (Brand, 2013, pp. 49-50). En la primera mitad del siglo xx no existían caminos para vehículos en la costa michoacana. En 1956 ya había 40 kilómetros de un camino todavía en construcción, desde las orillas del río Coahuayana (que hace frontera entre Colima y Michoacán) hasta el pueblo de La Placita en el municipio de Aquila. Y al otro lado de la costa ya se había construido un camino para camiones de carga desde el valle de Tepalcatepec hacia Arteaga, en la sierra, y a Playa Azul y el municipio de Melchor Ocampo. Pero la mayor parte de la costa, entre ambos extremos, aún no disponía de carreteras. Mayores datos aparecen en Monroy (2006). Es hasta la década de 1970 y 1980 cuando se construye una carretera que une a toda la costa michoacana (Reinberg, 2007).

${ }^{10}$ Región, la más extensa de la entidad, que está conformada por los distritos político-electorales de Coalcomán, Apatzingán, Salazar, Arteaga y Huetamo.

${ }^{11}$ En el marco modernizador del sexenio de Miguel Alemán Valdez (1946-1952) se crea por decreto presidencial, el 17 de julio de 1947, la Comisión de la Cuenca del Río Tepalcatepec, de la cual Lázaro Cárdenas sería su vocal ejecutivo. En 1960 sería sustituida por la Comisión del Balsas, también encabezada por Cárdenas hasta su muerte en 1970. Ambas comisiones tendrían por funciones impulsar en sus áreas de influencia proyectos de desarrollo (en materia agrícola e industrial), obras de aprovechamiento de riego, desarrollo de energía, escuelas, campañas sanitarias, vías de comunicación (carreteras, ferrocarriles, telégrafos), creación y ampliación de poblados. Y aunque sus principales acciones en Michoacán se centraron en la sierra de Uruapan, el valle de Apatzingán y la región calentana del Balsas, su impacto no dejó de hacerse sentir en el distrito de Coalcomán. Las vertiginosas obras de las comisiones hicieron en poco tiempo a una región "repulsiva" en "atractiva" y la migración se "tornó torrencial" desde mediados del siglo xx. La población se cuadruplicó en 30 años, y con ello también el hambre de más tierras. Véanse Calderón (2001, pp. 233-266) y González (2001, pp. 17-66).

\section{()(1) $(9$}


y su alianza con la familia Guillén, viejos líderes de la rebelión cristera en el suroeste de la entidad. ${ }^{12}$

En el municipio de Aquila se ubican cuatro de las cinco comunidades indígenas más importantes del distrito de Coalcomán: San Miguel Aquila, Santa María Ostula, Pómaro y Coire; mientras que en el municipio de Chinicuila, la de San Juan Huizontla.

Cochet (1991, pp. 110-134) ha ofrecido la mejor explicación del modo en que se fundó un modelo de desarrollo en la sierra y costa michoacana en términos agrarios. Rancheros y mestizos que fueron poblando en sucesivas oleadas al municipio de Coalcomán en el siglo xix desplazaron a las comunidades indígenas originarias de sus tierras y las fueron orillando hacia la periferia de la sierra y la costa a lo largo del siglo xx. En Coalcomán el desplazamiento fue total mientras que en otros municipios fue gradual y con diferentes matices. ${ }^{13}$ La resistencia indígena fue débil, salvo una matanza de mestizos ocurrida en 1935 y 1936 en Pómaro (Reinberg, 2007). A raíz de ello, los mestizos fueron sacados de las cabeceras de las tenencias municipales indígenas, donde ya habían penetrado. Pero nunca pudieron sacarlos de las tierras comunales invadidas. Por el contrario, el gobierno se empeñó en que fueran reconocidos como propietarios legítimos. Fue de ese modo como aparecieron los poblados de La Placita, El Salitre de Estopilas, San Pedro Naranjestil, Huahua, entre otros.

A los rancheros del distrito de Coalcomán, pese a que habían nutrido las filas de la rebelión cristera, el gobierno les reconoció su hegemonía en la región. ${ }^{14}$ Muchos de sus líderes conservaron el poder político y el liderazgo de las Defensas Rurales (cuerpos de civiles armados, subordinados al ejército).

${ }^{12}$ Un análisis más detallado del cacicazgo de los Guillén aparece en Gledhill (2004, pp. 276-280). También véase Alarcón (1998).

${ }^{13}$ Para las vicisitudes por las que atravesaron los diversos municipios del distrito, véanse también Figueroa (2008); Gledhill (2004); González (1966); Gutiérrez (2014); Marín (2007); Medrano (2004); Mora (2011); Núñez (2011); Reinberg (2007) y Topete (2017).

${ }_{14}$ Gledhill (2004) lo ha expresado así: "convertidos en caciques por la vía militar, lograron mantener su dominio regional después de la Cristiada" (p. 290), obligando al gobernador Lázaro Cárdenas (1928-1932) a reconocer su autoridad y llegar a un acuerdo político con ellos, que dejó la administración de importantes recursos en manos de grupos "que practicaban una subversión constante de sus proyectos de reforma para adecuarlos a los intereses y sensibilidades de sus seguidores". Véanse también Arreola (1980); Guerra (2015a); Purnell (1999) y Sánchez y Carreño (1979). 
Cochet (1991, pp. 200-211) aduce que entre 1950 y 1970 las obras emprendidas por las comisiones de Tepalcatepec $y$ la del Balsas provocaron intensos cambios en el suroeste michoacano. ${ }^{15}$ Barrett $(1975$, p. 145), por su parte, ha señalado que si bien la región experimentó cierto desarrollo con esas obras también dieron lugar a la generación de un "colonialismo económico": concentración de la riqueza en un polo y de la miseria en otro. ${ }^{16}$

El frágil equilibrio que se había mantenido entre indígenas y mestizos, tras la matanza de 1935 y 1936 en Pómaro, ${ }^{17}$ se rompió a partir de los años sesenta. En adelante, mestizos viejos y nuevos se niegan a pagar rentas a las comunidades indígenas y solicitan a las autoridades agrarias más tierras, a costa de los indígenas, cuyas propiedades no dejaban de sufrir invasiones. ${ }^{18}$ Las comunidades solían quejarse ante las autoridades, pero dada la ineficiencia de las formas legales o el retraso de las mismas,${ }^{19}$ decidieron emprender

${ }^{15}$ En la gran depresión de la Tierra Caliente las presas construidas "permitieron la constitución de grandes zonas irrigadas y el desarrollo de cultivos de exportación. Se crearon muchos ejidos y la población del valle se cuadriplicó entre 1950 y 1970" (Cochet, 1991, p. 200). Lo que no dejó de impactar al distrito de Coalcomán con nuevas oleadas migratorias que hicieron aumentar los cercamientos. Por ejemplo, en el caso de Pómaro, la llegada de "un nuevo contingente de agricultores aceleró la tala de bosques más cercanos al pueblo" y se abrieron nuevos espacios roturados para la agricultura, sobre los cuales "las cercas de alambre de púas han ganado terreno progresivamente, en grave perjuicio de las poblaciones indígenas. En 1979, las autoridades indígenas censan 41 fracciones indivisas cercadas con alambradas de púas: 34 pertenecen a mestizos y siete a miembros de indígenas de la comunidad". Y lo mismo pasó en San Pedro Naranjestil, donde todo el territorio terminó siendo "controlado por las familias mestizas" (Cochet, 1991, pp. 206-207).

${ }^{16}$ Arreola (1980, p. 267) precisa que, aunque el distrito de Coalcomán no era parte del programa de la comisión gubernamental, dada su cercanía geográfica al valle de Apatzingán y la iniciativa de sus pobladores, también alcanzó a verse beneficiado.

${ }^{17} \mathrm{Al}$ respecto, véase Reinberg (2007).

18 Cochet (1991, p. 213) detecta invasiones de tierras comunales por parte de los mestizos todavía en las décadas de 1970 y 1980. Véanse también Barrett (1975) y Reinberg (2007).

${ }^{19}$ Gledhill (2004) analizó detalladamente el caso de Ostula, comunidad que a diferencia de Pómaro, Maquilí o San Miguel Aquila, optó por cerrarse y no permitir la entrada de mestizos en su territorio, ni buscarlos como aliados. Y una estrategia similar a la de Ostula siguió la comunidad de Coire. De ahí, aduce Cochet (1991) que ambas comunidades no hayan sufrido cercamientos mestizos tan agudos. "La comunidad de Coire había expulsado a los mestizos después de las masacres de 1936 [...] pero los pueblos de Estopila y el Salitre de Estopila, situados al norte de los terrenos indivisos, fueron también rodeados de cercas" (p. 214). Por ese desplazamiento, "cada comunidad indígena dispone ahora de uno o varios "pueblos anexos' en la costa. Sólo Huizontla, rodeada desde hace ya más de un siglo por los ranchos privados, ha visto reducirse su espacio vital" (p. 214) sin tener una puerta de salida.

\section{(1) (1)}


también acciones directas: romper cercas, matar al ganado que encontraran y emplear la violencia contra los invasores.

Uno de los clivajes que detonaron oleadas de violencia fue el enfrentamiento entre mestizos y comunidades indígenas, pero otro de ellos fue el que se abrió entre estas últimas. Cada vez más orilladas hacia la costa, no dejaban de emprender mutuas invasiones reclamando viejos linderos. Las comunidades de Ostula, Coire y Pómaro se disputaban "ese macizo granítico costero, arenoso, seco y poco propicio tanto para la agricultura como para la ganadería" (Cochet, 1991, p. 218).

A medieros y pequeños propietarios mestizos les resultó más viable tratar de emular el modelo ranchero invadiendo tierras comunales indivisas, pues ello permitía rápido enriquecimiento con poca inversión. Además, al lado de esas fuentes de enriquecimiento siempre estuvo la posibilidad de invertir en otras actividades: siembra de enervantes, abigeato, agricultura intensiva. Este modelo de desarrollo predatorio no dejó de desencadenar espirales de violencia. No es casual que en la década de 1960 dos comisiones estatales y el propio comandante del sector militar de la región hayan tratado de promover pactos de no agresión entre las partes beligerantes.

El 25 de abril de 1963, en su calidad de presidente de una comisión gubernamental que visitó el municipio de Aquila, el profesor Manuel Chávez Campos (que además era jefe del Departamento de Quejas y Acción Social del Gobierno del Estado), rindió un extenso informe de 49 fojas al gobernador Agustín Arriaga Rivera. La comisión arribó a la zona a raíz de la denuncia de varios asesinatos en la región, especialmente en la comunidad indígena de Pómaro. ${ }^{20}$ De manera detallada daba cuenta de sus gestiones y recorridos en los poblados del municipio entre el 10 y 23 de marzo de ese año. Después de haberse reunido con mestizos, indígenas y autoridades municipales, llegaba a la conclusión de que la causa principal de la violencia y de todos los problemas que vivía el distrito de Coalcomán ("el de la criminalidad, el abigeato, falta de garantías, etc...") se hallaba en el "problema fundamental

${ }^{20}$ Presidente del Comité Ejecutivo Agrario del poblado de Huahua a Adolfo López Mateos, 18 de enero de 1964, donde el primero recuerda el asesinato de quince agraristas a principios de 1963 por no pagar rentas a la comunidad indígena de Pómaro. Fondo Secretaría de Gobierno. Sección Gobernación. Serie Aquila. Caja 1, exp. s/n, fs. 2-3. Archivo General e Histórico del Poder Ejecutivo de Michoacán (en adelante AGHpem), Morelia, México.

\section{()(1) $(9$}


de la tierra" y en las diversas violaciones al Código Agrario Vigente. ${ }^{21}$ Vale la pena detenerse en este informe tanto para dar cuenta de la problemática que se vivía como de las limitaciones que encontraban las autoridades para darle solución y encauzarla institucionalmente.

El 11 de marzo, en Aquila, la comisión recibió a varios grupos que solicitaban audiencia para exponer sus problemas: invasión de parcelas, agua para riego, etc., pero "el más grave" fue el de un numeroso grupo de campesinos solicitantes de tierra, que se les conocía como La Movida, pues se movilizan de un lado a otro en busca de acomodo y otros por tener cuentas con la justicia. Un acto "conmovedor" fue el de la madre de dos líderes agrarios de San Pedro Naranjestil, Juan y Custodio Farías, que no podían regresar al poblado por perseguirlos la familia Guillén, caciques de Pómaro. Su esposo había sido asesinado por los Guillén y sus hijos habían jurado vengarse (f. 5).

A las doce partió la comitiva rumbo a Maquilí para celebrar una junta con ejidatarios. Se abordó el problema de las invasiones de tierras a La Placita y se llegó al acuerdo de celebrar un "convenio de no agresión y de ayuda mutua”, entre ambos poblados, respetando los linderos que siempre habían reconocido, obligándose a aguardar "sin ningún problema, ni dificultad las dotaciones definitivas que la superioridad acuerde en su caso" (f. 6).

Esta fue la invariable solución que se encontró para dirimir los problemas en los poblados visitados: la firma de pactos de civilidad entre las partes. Se trataba de un esfuerzo por encauzar las diferencias a través del derecho y con ello "enfriar los conflictos". ${ }^{22}$ Sin embargo, en la práctica, dado que la

${ }^{21}$ Informe de la Comisión Gubernamental que visitó Aquila. 25 de abril de 1963. Fondo Secretaría de Gobierno. Sección Gobernación. Serie Aquila. Caja 1, exp. s/n, foja 34. AGHPEM, Morelia, México. La comisión estaba formada, además de su presidente, por el licenciado Antonio Sandoval Vega, secretario de la Comisión Agraria Mixta; el licenciado Juan Pineda Peñaloza, jefe de Averiguaciones Previas, adscrito a la Inspección General de Policía; un mayor del ejército, Othón Medina, en representación de la 21ㄹ Zona Militar; José Solórzano, procurador de Asuntos Indígenas; Feliciano González, representante de algunos grupos de campesinos solicitantes de tierras.

22 Bourdieu (2000) ha visto el papel civilizador del derecho: entrar en el campo jurídico implica aceptar su lógica de juego, "ponerse en manos del derecho para reglar el conflicto, es aceptar tácitamente la adopción del modo de expresión y de discusión que implica la renuncia a la violencia física y a las formas más elementales de la violencia simbólica, como la injuria" (p. 186). Empero, los actores del distrito de Coalcomán si bien incurrieron en el campo del derecho como un recurso para resolver sus disputas, no dejaron de renunciar del todo al uso de la violencia. 
"superioridad" tardaba mucho en resolver, serían las correlaciones de fuerza y la violencia el modo principal de dirimir disputas.

Así, en Coire la comisión promovió una asamblea ejidal en la que se acordó un pacto de ayuda mutua y no agresión con Ostula, de quien Coire venía sufriendo invasiones. Esa asamblea también revisó el problema agrario con El Salitre de Estopilas. Poblado que desde hacía más de 80 años se había formado rentando tierras de Coire. Desde hacía muchos años El Salitre venía luchando por liberarse de "esos tributos", y en "esa lucha casi salvaje por sanguinaria, perecieron muchos hombres [...] de ambas partes". Además, para obtener mayor fuerza, El Salitre se había convertido en un "verdadero centro de maleantes, asesinos, abigeos, traficantes de drogas, etc., por las facilidades que los dirigentes de esa comunidad daban a estos, a cambio de que en un momento dado hicieran armas en contra de la comunidad de Coire", sobre todo cuando se presentaran para exigirles el pago de la renta. Por si fuera poco, El Salitre estaba obligado a no sembrar sino pequeñas extensiones de tierra de maíz y frijol exclusivamente, pero debía abstenerse de sembrar palma, aguacate u otros frutales. Tras largas horas de deliberación la comisión aduce que logró convencer a comuneros de Coire de que era ilegal rentar tierras y de que era imposible correr a los habitantes de El Salitre. No había otro camino que reconocerlos como "comuneros con los mismos derechos y obligaciones que ellos tenían", pero proponía que dejaran fuera a todo aquel "que por su mala conducta fuera un peligro en la comunidad" y a quienes ahí se refugiaban evadiendo la ley (fs. 18 y 24 ).

Coire y Pómaro también tenían problemas de linderos entre sí. Pues por una equivocada resolución presidencial se tomaron tierras de casi la mitad del caserío de Pómaro para dárseles a Coire, estableciéndose una incesante lucha entre ambas comunidades. La comisión logró convencer a Coire de que cediera terrenos a Pómaro y que se establecieran nuevos linderos convencionales y esperar a que una nueva resolución presidencial los ratificase.

De Coire la comitiva se dirigió a Pómaro, su marcha fue a caballo y la jornada llevó trece horas por montañas y veredas quebradizas. El más grave problema que enfrentaba Pómaro, según la comisión, era el de la "administración de la tierra”. Pues si bien tenían sus bienes comunales confirmados por resolución presidencial desde 1960, al igual que en otros lugares desde hacía mucho tiempo la venían rentando a los mestizos, "adoptando el viejo sistema tributario de sus antepasados" (fs. 31-32). La comisión consideraba que se debía dejar de cobrar renta, pues ello era ilegal. Para lograr ese acuer-

\section{()(1) $(9$}


do, se invitó a los mestizos de San Pedro Naranjestil. Acuerdo de lo "más solemne e interesante". Pues Pómaro representaba "la comunidad que había sido escenario de cosas dantescas, asesinatos que por la forma como fueron corresponden a la época del salvajismo" (f. 35).

La comisión concluía su extenso informe pidiendo al gobernador que canalizará a las instancias correspondientes los acuerdos que se habían tomado, así como gestionar otras demandas que las comunidades habían solicitado (riego, luz, carreteras, escuelas y maestros). Pues sólo de esta manera, esa "apartada extensión territorial de la Entidad quedaría reintegrada al ritmo de trabajo y progreso del resto del Estado, desapareciendo en forma paulatina los gravísimos y añejos problemas que ha venido confrontando" (fs. 47-48).

Esos "gravísimos problemas" eran criminalidad, delincuencia, abigeato, pistolerismo y siembra de enervantes. Y todos ellos de algún modo, observaba con perspicacia la comisión, se interrelacionaban con los conflictos agrarios, provocando una espiral de violencia. A su vez, estos conflictos ocurrían no sólo entre comunidades indígenas y mestizos, sino también entre las propias comunidades indígenas que se acusaban mutuamente de invasiones de tierras y de no respetar linderos.

En otros municipios del distrito también se desarrollaban conflictos por la tierra, que asumían la forma de una lucha entre pequeños propietarios y ejidatarios o solicitantes de ejidos. Por ello, del 8 al 27 de abril de 1967 una nueva comisión gubernamental recorrió los municipios de Chinicuila, Aquila, Coahuayana y Melchor Ocampo. Esta llegó a conclusiones similares a las de su predecesora: la raíz de la violencia que se vivía en la zona giraba en torno al problema de la tierra. ${ }^{23}$ En Coahuayana encontró serias dificultades entre pequeños propietarios afectados por una resolución presidencial con que se dotaba a ejidatarios de Palos Marías y San Miguel del Río. Los primeros, aducía la comisión, se "han opuesto por medio de la violencia a que se lleve a cabo el deslinde dentro de tierras" que les fueron afectadas. Apoyados por el presidente municipal, han realizado "toda clase de actos violentos", en contra de los ejidatarios "y de los propios empleados del Departamento

${ }^{23}$ Gonzalo E. Pérez y García Piña a gobernador del estado. 2 de mayo de 1967. Fondo Secretaría de Gobierno. Sección Gobernación. Serie Aquila. Caja 3, exp. s/n, fs. 1-2. AGHPEM, Morelia, México. En Villavictoria, Chinicuila, por más que insistió la comisión gubernamental en que pequeños propietarios y ejidatarios encauzaran sus conflictos por la vía legal, no logró convencerlos de que depusieran sus intenciones belicosas.

\section{()(1) $(9$}


Agrario que se han presentado a practicar el deslinde", al cerrarles "el camino con grupo de gente armada". ${ }^{24}$

Como puede apreciarse, el camino del derecho y la vía institucional (firma de convenios y respeto a las leyes) parecía muy débil para encauzar la conflictividad social. Por ello, las partidas militares recorrían un vasto y difícil territorio intentando desarmar a los bandos contendientes, pero también ese mecanismo se mostraba deficiente. De ahí, que el uso de la violencia para dirimir diferencias no dejara de convertirse en uno de los recursos más empleados en el distrito. ${ }^{25}$

Recientemente, una corriente de la antropología ha enfatizado la noción de "márgenes del Estado" para aludir a espacios donde el Estado sólo está parcialmente presente y se muestra incapaz de instaurar el orden. Lugares donde no ofrece servicios eficientes: plena seguridad, buena infraestructura de comunicaciones, un adecuado flujo del comercio, calidad educativa, entre otras cosas. Lo que propicia que en algunas regiones o esferas, parte de la población viva en los "márgenes del Estado", en procesos de exclusión y de acusada desigualdad social que suelen generar violencia (Das y Poole, 2008, pp. 19-52; Maldonado, 2010, pp. 23-24;). ${ }^{26}$ Empero, en mi opinión, tales aspectos también pueden explicarse con las ideas de Michael Mann sobre la formación del Estado moderno: en ciertos ámbitos este aparece con una presencia más despótica (coercitiva) que infraestructural (hegemónica). En algunas regiones, los Estados tampoco han logrado ser la expresión de un sentimiento de ciudadanía compartido, puesto que tradicionalmente han sido más posesión de las elites, donde las masas no suelen sentirse bien representadas. Además, los servicios del Estado se desvían hacia intereses de las

${ }^{24}$ Fondo Secretaría de Gobierno. Sección Gobernación. Serie Aquila. Caja 3, exp. s/n, fs. 2-3. Aghrem, Morelia, México.

${ }^{25}$ Una lista de los asesinatos ocurridos en el periodo 1955-1966, entre los bandos beligerantes de Pómaro y Huahua aparece en acta ministerial del 22 de marzo de 1966. Sintomáticamente, otra acta ministerial del 11 de agosto de 1965, sobre el asesinato de tres miembros de la familia Guillén, no dejaba de recordar que la comisión gubernamental que visitó la región en 1963 hizo comprometerse a los jefes de ambos grupos a que dejaran de lado "las rencillas y el gobierno por su parte a no ejercitar acción penal en contra de nadie". Fondo Secretaría de Gobierno. Sección Gobernación. Serie Aquila. Caja 3, exp. s/n, fs. 1-2. AGHPEM, Morelia, México.

${ }^{26}$ Ciertas fallas en el mercado y el Estado propician intersticios en los que se gestan prácticas ilegales y violencia (Heyman y Smart, 1999, pp. 1-24).

\section{()(1) $(9$}


redes patrón-cliente de las elites políticas. ${ }^{27}$ De ahí, la aparición de fenómenos de "colonialismo económico" (Barrett, 1975).

Es justamente esa acusada debilidad infraestructural del Estado mexicano, lo que en parte explica que la conflictividad social que venía desbordando a las instituciones en el distrito de Coalcomán aún no desapareciera en la década de 1980. Un informe confidencial de un agente enviado por el gobernador Cuauhtémoc Cárdenas a la región afirmaba que la población mestiza de Huahua y San Pedro Naranjestil, seguía teniendo conflictos con la comunidad indígena de Pómaro. Los mestizos tenían "ganado, potreros, pastizales y propiamente se autogobiernan sin tomar en cuenta a las autoridades de la comunidad". Dominaban y abusaban de los indígenas. Las tierras las aprovechaban "con o sin el consentimiento de la comunidad". Además existían personas que "han cometido delitos y se refugian" en los poblados mestizos. Para resolver esos problemas y otros proponía: "Primero: Establecer una partida militar en Tizupan, para evitar el contrabando de marihuana, madera, productos del mar, combatir el abigeo y proteger el turismo entre otras... Segundo. Promover la construcción de un camino vecinal a San Pedro Naranjestil." 28

El agente ya no proponía convenios de no agresión, sino más presencia militar e integrar a esa porción del suroeste michoacano con mejores vías de comunicación (es decir, fortalecer más tanto el rostro despótico como el infraestructural del Estado). Sólo así, opinaba, se podían desactivar los ciclos de violencia y hacer frente a otros problemas delincuenciales. De hecho, hasta la fecha las tensiones continúan suscitándose entre mestizos e indígenas. ${ }^{29}$

27 Mann (2004, pp. 179-198) agrega que los Estados más eficaces son aquellos cuya sociedad es lo suficientemente igualitaria y homogénea como para permitir el desarrollo de un sentido común de ciudadanía. Los Estados pueden de ese modo desarrollar "poderes infraestructurales" efectivos para movilizar recursos y promover el desarrollo. Cree que los Estados en América Latina tienen fallas en esa dirección. Mann opina que hay dos sentidos en que puede entenderse un Estado fuerte: porque ejerce poder despótico o porque puede implementar de forma efectiva decisiones a través de la sociedad. El primero es un "poder sobre", el segundo es poder "a través de". El primero es un poder despótico, el segundo un poder infraestructural.

${ }^{28}$ Gregorio López a Cuauhtémoc Cárdenas. 11 de mayo de 1981. Fondo Secretaría de Gobierno. Sección Gobernación. Serie Aquila. Caja 5, exp. s/n. Aghpem, Morelia, México.

${ }^{29}$ Analizando el caso de la comunidad de Cachan de Echeverría, perteneciente a Pómaro, Figueroa (2008) señala: los conflictos entre "naturales" (indígenas) y mestizos "están marcados históricamente por la invasión de tierras, problemática que sigue vigente. No obstante, están en constante relación por cuestiones económicas, políticas e incluso de parentesco [...]

\section{()(1) $(9$}


Como una clara muestra de la debilidad infraestructural del Estado, especialmente en lo que concierne a los municipios de la costa-sierra, la mayoría de los estudiosos destacan el alto grado de marginalidad que aún padece la región (falta de apoyos gubernamentales, alcoholismo, pobreza, migración, criminalidad, violencia, entre otros aspectos). ${ }^{30}$

\section{LA OLA DELINCUENCIAL}

A la violencia agraria debe sumarse una violencia delincuencial que no había dejado de recorrer al distrito de Coalcomán desde la década de 1940. Si bien el tipo de violencia que fue referida en el anterior acápite tenía por protagonistas principales a comunidades indígenas y poblados mestizos, la delincuencial es llevada a cabo por bandas organizadas o delincuentes individuales que asolaban a la región. Las modalidades de esta violencia incluyen robos a hogares y comercios, secuestros, abigeato y asesinatos. También es posible apreciar una zona gris en la que se entrelazan diversos funcionarios locales, agentes judiciales e incluso algunos jefes de partidas militares que solían entenderse con las gavillas que operaban en el distrito.

El 26 de mayo de 1945 el presidente municipal de Aquila hizo saber al gobernador de la entidad que "ayer por la mañana un grupo de individuos armados" encabezados por los hermanos Andrés, Salvador y Fidel Gutiérrez Mendoza, vecinos de Maquilí, "asaltaron a unas familias y miembros de la Sociedad Cooperativa de Pequeños Productores de Sal [...] asesinando al Obrero Salinero Francisco Díaz Cisneros". Aunque se logró dar muerte a uno de los asesinos, afirmaba, como se carece de buena seguridad pública, "se temen nuevos asaltos". Pedía con urgencia la presencia de fuerzas federales, "toda vez que la partida que encabezan los Gutiérrez si no se les bate con energía hasta exterminarlos seguirán desolando la región”. El 5 de julio de ese mismo año, el presidente municipal de Aquila volvió a denunciar que la gavilla de los Gutiérrez, junto con la de "los Mancilla", el 13 de junio "asesinaron

\footnotetext{
algunas de estas relaciones han generado fuertes confrontaciones y negociaciones con grupos mestizos y actores gubernamentales, a partir de la intervención de estos en la cotidianidad local” (p. 354). Para el caso de Ostula, véanse Gledhill (2004) y Núñez (2011); sobre Coire, Mora (2011) y Reinberg (2007).

${ }^{30}$ Figueroa (2008); Gledhill (2004); Gutiérrez (2014); Marín (2007); Medrano (2004); Monroy (2006); Mora (2011); Núñez (2011); Reinberg (2007) y Topete (2017).
}

\section{()(1) $(9$}


al sr. Elías Valdez en la Zanja Prieta”. Reiteraba que los elementos que prestaban auxilio como policía municipal no tenían armas y que el comandante de la zona militar no había nombrado aun una partida de soldados, "estando esta región completamente avandonada [sic] a merced de los malhechores". ${ }^{31}$

En marzo de 1948 el síndico de Coalcomán, en su calidad de representante del Ministerio Público había solicitado el auxilio de las Defensas Rurales "para proceder a la captura de varios individuos responsables del delito de homicidio", pero la respuesta de la comandancia militar fue "que no era misión de las Defensas Rurales desempeñar funciones de policía urbana" ${ }^{32}$

La comunidad de Coire, por su parte, solicitaba se le autorizara la formación de una Defensa Rural, "con armas particulares [...] porque se han registrado crímenes y el pueblo se encuentra sin garantías”. Y, en caso de que ello no se autorizara, que se les permitiera al menos organizar un cuerpo de "auxiliares con carácter de Policías con servicio gratuito". Es decir, pagado por la comunidad. ${ }^{33}$

La Asociación de Pequeños Propietarios y Ganaderos de Coalcomán, ${ }^{34}$ dirigió el 4 de julio de 1953 una encendida carta al gobernador denunciando la presencia de otra gavilla, que disfrazados de militares asolaba a la sierra. Primero habían asaltado el domicilio del "compañero Miguel Mendoza Ochoa en el rancho de Piedras de Lumbre", "saquearon la casa llevándose todo lo de valor" y secuestraron a su propietario, a quien luego dieron muerte. Posteriormente, repitieron la acción en los domicilios de "los compañeros Marcial y Agapito Ramírez”, a quienes se llevaron secuestrados. De la casa de Rodolfo Mendoza, a quien plagiaron, se "llevaron alhajas de la familia y 5000 " pesos en efectivo, "producto de la venta reciente de una engorda de cerdos". Luego se internaron en la sierra. En el camino liberaron a Antonio Mendoza para que fuera con los familiares a pedir rescate de 100000 pe-

\footnotetext{
${ }^{31}$ Fondo Secretaría de Gobierno. Sección Gobernación. Serie Aquila. Caja 1, exp. s/n. AGHPEM, Morelia, México.

32 Oficio transcrito del síndico Antonio Robledo Orozco al procurador general de Justicia de Michoacán, 10 de abril de 1948. Fondo Secretaría de Gobierno. Sección Gobernación. Serie Coalcomán. Caja 8, exp. 154. AGHPem, Morelia, México.

${ }_{33}$ Presidente del Comité de Bienes Comunales de Coire al gobernador. 28 de julio de 1950. Fondo Secretaría de Gobierno. Sección Gobernación. Serie Coalcomán. Caja 8 , exp. 154. aghpem, Morelia, México.

${ }^{34}$ Creada a fines del sexenio presidencial de Lázaro Cárdenas. Desde su fundación venía cooperando con las autoridades en el combate al abigeato y en obras de infraestructura (Arreola, 1980, p. 272).
}

\section{()(1) $(9$}


sos por la vida de Agapito Ramírez. El jefe de dicha gavilla era "el conocido bandolero Salvador Mendoza Madrigal", misma que llevaba tiempo siendo un azote en la sierra, pues además de abigeato, "saquean, roban, asesinan y plagean $[s i c]$ a personas honorables exigiéndoles préstamos hasta convertirse en un serio peligro" para la población. ${ }^{35}$

En 1956, en el municipio de Aguililla, el jefe de la policía judicial de la entidad encabezó a un grupo de judiciales que lograron realizar "varias aprehensiones de delincuentes", pero tropezó con la dificultad de no poderlos consignar debido a que el representante del Ministerio Público de ese lugar, Rodolfo Carrasquedo Bustos, pese a las súplicas del jefe de policía para que le recibiese las consignaciones, se ausentó sin motivo alguno. El presidente municipal solicitaba al gobernador que llamase la atención a ese servidor público por entorpecer "la acción de la justicia". ${ }^{36}$

Algo similar estaba ocurriendo en el municipio de Coahuayana, donde una partida militar fue recibida a tiros, al tratar de aprehender a una banda de delincuentes integrada por Adán Bravo, Búlmaro Cuevas y Francisco Bravo, entre otros, por los "frecuentes robos y asesinatos" que cometían. Los militares lograron la captura de los mismos e hirieron al primero de ellos. Asimismo, Pablo Mendoza y José Guizar, miembros de otra banda de asaltantes, el 7 de febrero de 1962 "dispararon sus armas sobre una camioneta produciéndole noventa impactos". Después del asalto los delincuentes "dijeron haberse equivocado de vehículo y ese detalle facilitó la aprehensión de los mencionados", pero resultaron muertos "al tratar de fugarse". Además, el general Salvador Rangel Medina, comandante del batallón 49, con sede en Apatzingán, se quejaba de que el agente del Ministerio Público de Coahuayana estaba convirtiendo las consignaciones que recibía "en fuente de ingresos personales". Proceder que dio lugar a que el comandante de la partida militar y la propia policía municipal del poblado, "dejaran de prestarle su colaboración en la búsqueda de delincuentes". ${ }^{37}$

\footnotetext{
${ }^{35}$ Fondo Secretaría de Gobierno. Sección Gobernación. Serie Coalcomán. Caja 1, exp. 7. AghPem, Morelia, México.

${ }^{36}$ Presidente Municipal de Aguililla a gobernador. 24 de marzo de 1956. Fondo Secretaría de Gobierno. Sección Gobernación. Serie Aguililla. Caja 1, exp. 13. AGHPEM, Morelia, México.

${ }^{37}$ General Salvador Rangel Medina a comandante de la Xxi zona militar. 31 de diciembre de 1962. Fondo Secretaría de Gobierno. Sección Gobernación. Serie Apatzingán. Caja 2, exp. s/n. Aghrem, Morelia, México.
}

\section{()(1) $(9$}


En 1966 la comunidad de Coire manifestaba que "desde hace tiempo" se habían estado registrando "algunos asesinatos", sin que hasta la fecha se haya podido capturar a los delincuentes, que se refugiaban en El Salitre de Estopilas. Además, en los meses de abril y mayo de ese año hubo robos de "semovientes vacunos". 38

El 13 de noviembre de 1967, el presidente municipal de Aquila envío un extenso informe al agente del Ministerio Publico, Raymundo Plascencia Téllez, detallando los delitos ocurridos en el municipio. En el poblado de la Mina de la Providencia se registró un asalto a mano armada por seis personas desconocidas en la casa de Rafael Reyna, "saqueándole 2 pistolas... y un flower 22 automático". En Maquilí, a José Chávez se le introdujo a su comercio el delincuente Dimas Bustos Rivera, quien le robó alrededor de 600 pesos. Además, se ha comprobado que este ha estado cometiendo atracos en Coahuayana, Villavictoria y Coalcomán, "acompañado de un grupo de maleantes que se hacen pasar por Agentes de la Judicial", sustrayendo en diversos domicilios armas, alhajas y dinero en efectivo. A otra banda de delincuentes que operaba en Aquila no se le había podido identificar porque se cubren el rostro con máscaras de tela de mezclilla, pero la población sospechaba que el cabecilla era José Acevedo Guizar del poblado La Palmita, municipio de Aquila. Su modo de operar era caer por sorpresa en algún poblado. Tras cada golpe sus miembros se dispersaban, refugiándose en diversas rancherías con algún pariente. Luego, "después de pasar los días se vuelven a reunir para dar un nuevo golpe a cualquier ranchería [...] de los Municipios circunvecinos". Todas esas bandas, concluía el escrito, "recaen en indefensos campesinos que viven en partes alejadas de toda comunicación, garantía y protección de la justicia”. Por lo cual, urgía el envío de una partida militar. ${ }^{39}$

Lo anterior es una clara muestra de que la deficiencia infraestructural del Estado (aislamiento de ciertas comunidades, falta de adecuadas comunicaciones y de "garantías y protección de la justicia"), propiciaba olas delincuenciales.

El ambiente de intranquilidad también se hacía sentir en Las Trojes, Coalcomán, donde había "numerosos maleantes". Por ello, la Secretaría de

\footnotetext{
${ }^{38}$ Jefe de Tenencia Municipal de Coire a procurador de Justicia del Estado. 8 de noviembre de 1966. Fondo Secretaría de Gobierno. Sección Gobernación. Serie Aquila. Caja 2, exp. s/n. Aghrem, Morelia, México.

${ }^{39}$ Fondo Secretaría de Gobierno. Sección Gobernación. Serie Aquila. Caja 3, exp. s/n. AGHPEM, Morelia, México.
}

\section{()(1) $(9$}


la Defensa Nacional (Sedena) ordenó en septiembre de 1970 el envío de un pelotón de Defensas Rurales para que colabore con las autoridades locales en "el mantenimiento del orden y la tranquilidad en la región". ${ }^{40}$ Empero, el pelotón estuvo poco tiempo en el poblado. Cinco años más tarde, el presidente municipal de Coalcomán se quejaba ante el gobernador, que la SEDEna se había negado a enviar a Las Trojes una partida militar, con el argumento de que "las unidades se encontraban en adiestramiento". Pero como era "incontrolable la frecuencia de escándalos y delitos en aquella región, apropiada para refugio de toda clase de maleantes y criminales", rogaba al gobernador que por lo menos enviase "elementos de la policía judicial" para que impusiesen el orden en toda esa zona, pues "como existen muchas Comunidades Agrarias cercanas a este lugar, hay bastante concurrencia de gentes y es cuando criminales y maleantes hace su agosto porque no le temen a ninguna autoridad". Además, muchos habitantes se prestaban a proporcionar "las comodidades necesarias al grupo [de maleantes] con tal de que acabe la penosa situación por que atraviesan". ${ }^{41}$

En San Pedro Naranjestil y en Huahua, municipio de Aquila, había "muchos maleantes, asesinos, asaltantes, ladrones y abigeos", que forman gavillas. El agente del Ministerio Público Pascual Arteaga Pimentel informaba, el 9 de enero de 1971, al procurador general de Justicia que los habitantes de esos poblados vivían en "constante zozobra", al no contar con las garantías mínimas de seguridad. Desde la cabecera municipal, a "esos puntos hay que andar tres días a marcha forzada a caballo para llegar, son puntos apartados de toda comunicación, hay muchos parajes solitarios y terrenos accidentados, donde siempre habitan los criminales". Pedía con urgencia el envío de partidas militares a esos poblados. Pues en diciembre de 1970 habían ocurrido cuatro asesinatos y dos robos a mano armada. ${ }^{42}$

Ese clima de inseguridad no frenó hasta bien entrados los años setenta. El 6 de junio de 1979, numerosos vecinos de Aquila, desesperados, soli-

${ }^{40}$ General Salvador Cruz Calvo a capitán 2º de Caballería. 19 de septiembre de 1970. Fondo Secretaría de Gobierno. Sección Gobernación. Serie Coalcomán. Caja 1, exp. 7. AGHPEM, Morelia, México.

${ }^{41}$ Presidente municipal de Coalcomán a gobernador. 10 de agosto de 1975. Fondo Secretaría de Gobierno. Sección Gobernación. Serie Coalcomán. Caja 4, exp. s/n. AGHPEM, Morelia, México.

${ }^{42}$ Fondo Secretaría de Gobierno. Sección Gobernación. Serie Aquila. Caja 4, exp. s/n. Aghrem, Morelia, México. 
citaron al comandante de la zona militar el envío de una partida de soldados, con la finalidad de que "restablezca y conserve el orden y la paz pública en esta región", que vivía "amenazada por una plaga de individuos carentes de respeto, ebrios, escandalosos y braveros, que hacen cuanto les viene en gana", aprovechándose de la debilidad e incluso de la "complicidad" de la policía municipal. "Es desesperante presenciar actos de individuos que sin ningunos miramientos de moralidad penetren fortivamente [sic] a domicilios de gente humilde y siembren el terror en sus moradores." Enfatizaban que parecían vivir en una época de "incertidumbre parecida a los tiempos" de José Inés Chávez García, un famoso bandolero de la década de 1910. ${ }^{43}$ "En suma, el cuadro de nuestra vida es doloroso y de un porvenir desalentador. Somos víctimas de toda clase de abusos y atropellos. Vivimos a merced de los maleantes." ${ }^{4}$

A principios de la década de 1980, seguía habiendo indicios de que las actividades delincuenciales estaban lejos de disminuir. Un agente confidencial del gobernador Cuauhtémoc Cárdenas recorrió cinco municipios de la zona y rindió un informe poco alentador. Tanto en Aquila como en Coahuayana, había un agente del Ministerio Público, Armando Rodríguez Bueno, que "protege a una banda de maleantes, encabezados por Antonio Lazo", que operaba en el poblado de La Placita y en toda la región. Coahuayana y Aquila se encontraban "a merced de los abigeos y asesinos, existe mucho pistolerismo permitido por los elementos de la policía judicial". El presidente municipal de Coahuayana, informaba el agente, solicitaba el envío de elementos de la policía judicial, pero que no fueran "Agentes que nada más vayan a llenarse los bolsillos de dinero, como ya ha sucedido dejando ciertas libertades a los maleantes". En suma, en lo que concernía a seguridad pública, en los cinco municipios que fueron visitados (Aquila, Coahuayana, Coalcomán, Chinicuila y Tepalcatepec) "se carece de organización en las filas de la policía, razón por la cual no existe Seguridad Pública”. ${ }^{45}$ Era un contundente

${ }^{43} \mathrm{Al}$ respecto, véase Ochoa (1990).

${ }^{44}$ Fondo Secretaría de Gobierno. Sección Gobernación. Serie Aquila. Caja 5, exp. s/n. Aghpem, Morelia, México. El 21 de febrero de 1977, también el presidente municipal de Chinicuila solicitaba al gobernador una partida militar, "ya que es muy necesaria para guardar el orden dentro de la población”. Fondo Secretaría de Gobierno. Sección Gobernación. Serie Chinicuila. Caja 4, exp. s/n. Aghrem, Morelia, México.

${ }^{45}$ José M. Meza Robles a Cuauhtémoc Cárdenas. 14 de noviembre de 1981. Fondo Secretaría de Gobierno. Sección Gobernación. Serie Aquila. Caja 5, exp. s/n. Aghpem, Morelia, México. 
reconocimiento de que el Estado no brindaba una eficiente protección a la ciudadanía.

\section{LA LUCHA CONTRA LOS ENERVANTES}

En 1959 arribó a Apatzingán el batallón 49, comandado por el general Salvador Rangel Medina. Venía con órdenes del presidente Adolfo López Mateos de combatir a las numerosas gavillas de maleantes que operaban en el suroeste michoacano, así como para realizar una campaña contra el cultivo y tráfico de enervantes en la región. El biógrafo del general Rangel, quien tuvo acceso a sus memorias y archivo personal, señala que la experiencia de Rangel y sus tropas en el combate al narcotráfico era prácticamente "nula". "No existían antecedentes sobre ese tipo de campañas para analizar y tomar lecciones, por lo que había que diseñar una estrategia propia." La etapa que estaba por comenzar con el tiempo sería considerada como "la primera campaña del ejército contra el narcotráfico" (Veledíaz, 2012, pp. 2269 y 2128).

Al principio, Rangel sufrió algunos descalabros, al ser emboscadas sus tropas en varios de sus recorridos por la sierra, sufriendo algunas bajas. Pronto descubrió que quienes se dedicaban al narcotráfico tenían amistades con caciques y algunas autoridades locales. Se dio cuenta de que el batallón necesitaba de la ayuda de informantes y guías conocedores del terreno, "que en lo individual podían ser estimulados con armas o dinero para que se sintieran unidos al personal castrense, sin que se les cuestionaran sus antecedentes", pues algunos habían sido delincuentes, o incluso habían estado ligados al cultivo de enervantes (Veledíaz, 2012, p. 2067).

Rangel dividió a sus tropas en varias patrullas destinadas a recorrer diversas comunidades y él se reservó las que estaban en la zona indígena, las más incomunicadas y marginadas. A su llegada a ellas, le recordaron que los militares ya habían estado en sus poblados y terminaron como "incondicionales de los caciques" (Veledíaz, 2012, p. 2082). Con miras a ganar el apoyo de la población, el general no dejó de realizar con sus tropas cruzadas sanitarias, educativas y brindar diversas clases de ayuda a las comunidades. ${ }^{46}$

\footnotetext{
${ }^{46}$ Por ejemplo, en el boletín número 11 de 1964 señalaba que en lo que concierne a "los trabajos de carácter social" iniciados el año anterior el batallón no ha dejado sin atender "ningún punto de la costa ni de la sierra, llevando en todos los casos" obras "en materia de
}

\section{(1)(1) $(9$}


Localizar plantíos en las décadas de 1950 y 1960 era muy difícil, pues no se disponía de helicópteros, ni de apoyo fotográfico. Los sembradíos no solían estar a la vista, ni en lugares poblados. Hallarlos implicaba llegar hasta el fondo de cortaduras y barrancas en lo más recóndito de las montañas. Un método era seguir las corrientes de agua en los acantilados, lo que implicaba enorme desgaste de energía a fuerza de bajar y trepar pendientes y desfiladeros. Y no pocas veces solían ser presas de emboscadas (Veledíaz, 2012, pp. 2158-2168).

Pero pronto, con la asistencia de guías locales, las tropas pudieron detectar sembradíos de enervantes y pistas clandestinas. En su estancia en el suroeste michoacano, Rangel escribió un boletín mensual destinado a estimular la moral de sus tropas y a narrar las actividades de las mismas, al que tituló Tres Palabras. A fines de 1962, afirmaba que ese año "bien podemos llamarlo el de las operaciones exitosas en todo lo que nos propusimos realizar en todos sus aspectos". En materia de enervantes se hicieron en la sierra las operaciones Estopila, Marcelino, Chupamirto, Changunga, Comanche, Amistad y Cardoso, que dieron como resultado la destrucción de 157 hectáreas sembradas de amapola y de 21 de mariguana, aparte "de los plantíos destruidos por sus propios sembradores antes de nuestra llegada". Y fueron más de 40 los traficantes consignados. Además, se implementó "un sistema pueblerino de espionaje" y varios soldados "volvieron a sus días de huarache y calzón blanco". ${ }^{47}$

Sin embargo, en el boletín número 11 de ese mismo año, Rangel se lamentaba de que en Aguililla una patrulla militar iba camino a destruir un plantío de mariguana de poco más de 1000 metros, pero el encargado del orden dio el pitazo a tiempo y cuando llegaron los soldados "sólo encontraron los troncos de las matas, pues ya les habían quitado todas las ramas". ${ }^{8}$ No sería la única muestra de colusión entre autoridades locales y traficantes que hallaría Rangel. En 1965 se quejaba de que se requería de mayor coope-

construcción de locales para escuelas y arreglo y acondicionamiento de las ya asistentes", así como campañas sanitarias, dentales, obsequio de medicinas y de máquinas de coser. Fondo Secretaría de Gobierno. Sección Gobernación. Serie Apatzingán. Caja 7, exp. s/n. AGHPEM. Morelia, México.

47 Tres Palabras, número 12, 1962. Fondo Secretaría de Gobierno. Sección Gobernación. Serie Apatzingán. Caja 2, exp. s/n. AGHPem, Morelia, México.

${ }^{48}$ Fondo Secretaría de Gobierno. Sección Gobernación. Serie Apatzingán. Caja 7, exp. s/n. AGHPEM, Morelia, México.

\section{()(1) $(2$}


ración de las dependencias oficiales directamente interesadas en el combate a traficantes y maleantes. Exponía el caso de tres individuos que habían sido aprehendidos por narcotraficantes, tras una larga búsqueda y, en un tiempo menor al de su traslado y consignación, fueron liberados. Ello ocasiona, expresaba, "que se debilite la moral en las tropas y poca fe en la justicia por parte de la población, además de que hace peligrar a los guías e informantes locales que ayudan al ejército a realizar las aprehensiones". ${ }^{49}$

A pesar de todo, el general consideraba que en su estadía en el suroeste michoacano (1959-1965) se logró erradicar "la siembra de enervantes". Y seguirá siendo así, expresaba en un lenguaje socarrón, "siempre y cuando la vigilancia sea permanente para evitar toda posibilidad de que muchos antiguos sembradores que hace poco salieron de la cárcel por haber cumplido sus condenas, se sientan con ganas de repetir el colorado". Concluía su último boletín ofreciendo datos estadísticos que habían alcanzado sus campañas militares: destrucción de 416 hectáreas de siembra de amapola; 32 de mariguana; un poco más de 18 kilos de goma de opio decomisados y dos automóviles junto con sus respectivas cargas de droga. Si tomamos en cuenta, aducía, que cada plantío era de pequeñas dimensiones y se encontraba escondido entre las barrancas, "reconocemos el esfuerzo realizado por las numerosas patrullas que por arriba y por debajo de los cerros anduvieron explorando y destruyendo plantíos" hasta lograr las cifras alcanzadas. ${ }^{50}$

Pero la siembra de enervantes en el distrito estaba lejos de ser erradicada. En 1973, por ejemplo, fue descubierta en el rancho El Aguacate, Aguililla, una pista clandestina que se utilizaba para transportar estupefacientes. A tal descubrimiento se llegó luego de que una avioneta cargada con marihuana sufriera un accidente, pereciendo el piloto estadunidense que la conducía. ${ }^{51}$

Un agente confidencial del gobernador de la entidad enviado a la región en 1981 informaba que en la zona había "contrabando de marihuana,

\footnotetext{
${ }^{49}$ Boletín número 1, 1965. Fondo Secretaría de Gobierno. Sección Gobernación. Serie Apatzingán. Caja 7, exp. s/n. AGHPEM, Morelia, México.

50 Boletín número 6, 1965. Fondo Secretaría de Gobierno. Sección Gobernación. Serie Apatzingán. Caja 8, exp. s/n. AghPeM, Morelia, México.

${ }^{51}$ General Jorge Castellanos Domínguez, jefe de $21^{a}$ zona militar, a secretario de la Defensa Nacional. 23 de diciembre de 1973. Fondo Secretaría de la Defensa Nacional (en adelante SedenA). Estado Mayor. Quejas. Caja 85/77457/6, exp. 608-1974. Archivo General de la Nación (en adelante AGN), México.
} 
madera, ${ }^{52}$ productos del mar [...y] abigeato". Para su combate proponía mayores partidas militares. ${ }^{53}$ Otro informe confidencial de un agente de la policía judicial, tras sus pesquisas encontró que había fuertes rumores de que el presidente municipal de Chinicuila, J. Jesús García Esparza, "tenía nexos con traficantes de drogas", y aunque no pudo comprobar nada, sí encontró que en el rancho El Cipino y en la Barranca del Mamey, había sembradíos de marihuana. Lugares donde radicaba un compadre del presidente municipal, Everardo Rivera Birrueta, que la población señala como "presunto traficante de drogas". ${ }^{54}$

\section{EL PISTOLERISMO Y LAS VENDETTAS}

Una presencia infraestructural muy débil del Estado en el suroeste michoacano, aunado al grado de aislamiento de la región y de su poco desarrollo económico, propiciaron una cultura del honor y de vendettas muy arraigada. ${ }^{55}$ No es casual que el general Salvador Rangel señalara que la lucha contra

52 En 1954 la empresa forestal Compañía Michoacana de Occidente obtuvo la concesión para explotar durante 25 años los bosques de Coalcomán, Aguililla, Tumbiscatío y Arteaga, con el compromiso de introducir técnicas modernas, realizar obras de beneficio social (carreteras hasta la costa, casas para los obreros, centros de salud y escuelas). Pero la empresa incumplió sus promesas. Por lo cual, campesinos y pequeños propietarios iniciaron una lucha contra ella, exigiéndole cumpliera con sus compromisos, así como para que se les permitiera explotar los bosques, en alianza con el gobierno. Tras una larga lucha, los campesinos lograron que se les concediera la creación del ejido forestal El Varaloso y Barranca Seca. El gobierno decidió no renovar la concesión a la empresa. Lázaro Cárdenas no dejó de lanzar encendidas críticas a la empresa y apoyar a los ejidatarios (Arreola, 1980, pp. 268-269). También llegaron a la región empresas madereras germanas, japonesas y estadunidenses, que incluso "de manera clandestina buscaron explotar tierras comunales" (Mora, 2011, pp. 6869). Posiblemente, algunas de estas empresas estaban detrás del contrabando de madera que denunciaba el agente. En todo caso, ello es otro indicador de la debilidad infraestructural del Estado para hacer cumplir la ley.

${ }^{53}$ Gregorio López al gobernador Cuauhtémoc Cárdenas. 11 de mayo de 1981. Fondo Secretaría de Gobierno. Sección Gobernación. Serie Aquila. Caja 5, exp. s/n. AGHPEM, Morelia, México.

${ }^{54}$ José Juan Pérez Sánchez, jefe de grupo de la policía judicial estatal, a director de la Policía Judicial del Estado. 18 de abril de 1985. Fondo Secretaría de Gobierno. Sección Gobernación. Serie Chinicuila. Caja 3, exp. 16. Aghpem, Morelia, México.

55 Spierenburg (2008, pp. 259-272) afirma que, en la Europa occidental del medievo al presente, las bases del honor, en particular del masculino, cambiaron de una fuerte asociación con el cuerpo a una mayor conexión con la virtud ("espiritualización del honor"). Con- 
los enervantes no fue el principal desafío que encontró el batallón 49, sino el combate al pistolerismo, los esfuerzos por desarmar a la población civil. ${ }^{56}$ En mi opinión, ello era así porque los tipos de violencia que hemos referido en los anteriores acápites son expresiones de una violencia instrumental, el pistolerismo, en cambio, es un caso más cercano a la violencia ritual: ligado al habitus, ${ }^{57}$ a los juegos de virilidad, honor y vendettas. Por ello, Rangel tenía la impresión de que estaba ante un escenario parecido al del viejo oeste estadunidense, en el que imperaba la ley del revolver. ${ }^{58}$

Por ejemplo, en Aguililla la familia Gil y la familia Mendoza habían mantenido una larga historia de vendettas. El 17 de agosto de 1955, la primera de ellas escribió al gobernador Dámaso Cárdenas para manifestarle su intención de frenar esa espiral de violencia entre las partes: "Queremos que los derramamientos de sangre que ha habido entre nuestra familia y la familia Mendoza, definitivamente lleguen a su fin." Por su parte se comprometían "a no agredir, pero queremos también no ser agredidos" en bien de nuestros hijos. Pedían la mediación del gobernador "para que nos ayude a que estas viejas rencillas sean liquidadas". ${ }^{59}$

Ese mismo año, el director de la escuela rural federal de Aguililla, Enrique Guido Villalpando, hizo saber al comandante de la $21^{\mathrm{a}}$ zona militar que en el municipio los "portadores de armas" tan luego ven llegar una partida militar las esconden, "y no bien se han alejado vuelven los escándalos y

secuentemente, la necesidad de emplear la violencia en orden a salvar la cara cuando se es insultado o desafiado tendió a disminuir. El concepto de honor ligado al cuerpo aparece más en sociedades que carecen de un sistema estatal estable y de una economía poco diferenciada, mientras que el movimiento hacia la espiritualización del honor aparece durante lapsos temporales en que la pacificación trae un Estado estable y arraigado institucionalmente.

${ }^{56}$ Boletín Tres Palabras, número 11, 1962. Fondo Secretaría de Gobierno. Sección Gobernación. Serie Apatzingán. Caja 2, exp. s/n. AGHPem, Morelia, México.

${ }^{57}$ Se trata de un concepto de Bourdieu, por el cual debe entenderse un conjunto de relaciones históricas "depositadas" dentro de los cuerpos de los individuos (agentes), bajo la forma de esquemas mentales y corporales de percepción, apreciación y acción (Bourdieu y Wacquant, 2008, pp. 41-42). Según Elias (1999), los habitus, dada su naturaleza poco maleable, son difíciles de cambiar y para percibir sus cambios se requieren por lo menos tres generaciones.

${ }^{58}$ Rangel recordaba que en el suroeste michoacano había un clima conflictivo por "falta de garantías" hacia la ciudadanía, pues "como en tiempos del lejano oeste prevalecía la ley del más fuerte". Existía "un pistolerismo desbordado, los homicidios eran frecuentes y se multiplicaban asaltos, robos de ganado y siembra de droga" (Veledíaz, 2012, p. 1823).

59 Apolinar Gil a Dámaso Cárdenas, 17 de agosto de 1955. Fondo Secretaría de Gobierno. Sección Gobernación. Serie Aguililla. Caja 1, exp. 12. AGHPEM. Morelia, México.

\section{()(1) $(9$}


los disparos". Consideraba que más de 75\% de la población adulta masculina "tienen ya sea pistola, rifle cal. 22 aut., rifle cal. 44 o retocarga, etc.", por lo que los "zafarranchos" son frecuentes. Señalaba que urgía una partida militar permanente en el poblado. ${ }^{60}$

En 1963, la comunidad de Coire hizo llegar al gobierno del estado un acta en la que consignaba la lista de asesinatos cometidos por los vecinos de El Salitre de Estopilas desde la década de 1930, detallando nombres y circunstancias en que fueron llevados a cabo: en 1935 se cometieron tres asesinatos; en 1937 fueron once; en 1938 dos soldados de una partida que realizaban un recorrido fueron abatidos; en 1940 se asesinó a dos personas, cifra que se repitió en 1941 y 1948; en 1951 sólo hubo uno; pero en 1957 y 1958, la cifra fue de dos por año; en 1960 cuatro soldados de una partida militar fueron abatidos y en 1961 la cifra fue de dos homicidios. ${ }^{61}$

El presidente municipal de Aquila informó al gobernador, el 9 de septiembre de 1964, que por "la incultura y las costumbres ancestrales del medio rural de esta apartada región michoacana, y a veces por necesidad, la mayoría de los hombres que ocurren a esta cabecera [...] portan armas de fuego", sin que el Ayuntamiento pueda "reprimir esta mala costumbre" por no contar ni con armas, presupuesto, ni policía municipal suficiente y capaz. Y resulta que cuando las personas se encuentran con sus rivales "ajustan cuentas a mano armada ocasionando cuantiosos saldos de sangre", como los habidos el pasado 5 de septiembre, en que perdió la vida el propio comandante de la policía de El Salitre de Estopilas. Otras veces, dichos individuos "beben demasiado y provocan balaceras y escándalos mayúsculos, sin que nadie les pueda llamar la atención, y provocan el pánico entre las personas del pueblo". ${ }^{62}$

Algo parecido ocurría en Chinicuila, donde "se vienen cometiendo grandes escándalos con armas de fuego" y debido al "pistolerismo que abunda en la región, con frecuencia y con mucha facilidad se cometen homicidios,

${ }^{60}$ Enrique Guido Villalpando a general Félix Ireta. 19 de noviembre de 1955. Fondo Secretaría de Gobierno. Sección Gobernación. Serie Aguililla. Caja 1, exp. 12. AGHPEM, Morelia, México.

${ }^{61}$ Acta informativa de la comunidad de Coire dirigida al Departamento de Quejas y Prevención del Gobierno del Estado. 1 de marzo de 1963. Fondo Secretaría de Gobierno. Sección Gobernación. Serie Aquila. Caja 1, exp. s/n. Aghpem, Morelia, México.

${ }^{62}$ Fondo Secretaría de Gobierno. Sección Gobernación. Serie Aquila Caja 2, exp. s/n. AGHPem, Morelia, México. 
raptos" de mujeres, entre otras cosas, que causaban alarma en la población. ${ }^{63}$ El propio magisterio denunciaba que en el municipio desde hace tiempo se vive con "demasiada intranquilidad debido a los considerables homicidios y escándalos en vía pública. Es sumamente triste ver cantidad de niños en plena orfandad [a] consecuencia de tanto asesinato". Además de que el lugar carece de centros de distracción, "las familias se privan de salir siquiera los días domingos al jardín, por temor a los escándalos y disparos de armas", que en plena plaza se registraban. ${ }^{64}$

La Cofradía de Ostula, a raíz de la celebración de la fiesta del día del niño, solicitaba, a través de un agente del Ministerio Público, el envío de una partida militar, "con la finalidad de guardar el orden y la tranquilidad pública durante el baile en la localidad", ya que en diversas ocasiones "se han suscitado varios zafarranchos en los que han perecido varios individuos [...]. Esto se debe a que personas circunvecinas que dicen ser valentones bajan a los bailes [...] con las armas de fuego de diferentes calibres, desafiando a ciertas personas". ${ }^{65}$

El presidente municipal de Coalcomán se quejaba de que el ejército en sus campañas de despistolización desarmaba a los encargados del orden, sin respetarles sus credenciales expedidas para portar armas. Por lo que amenazaban con renunciar si no se les respetaba su cargo. Recordaba al gobernador que de sobra él conocía cual era la situación que prevalecía en el campo: "son gentes rudas, acostumbradas a traer armas con permiso o sin él, tardan más en decomisárselas que en traer otra, prefieren traer sus armas de fuego a to-

${ }^{63}$ Presidente municipal de Chinicuila a gobernador. 31 de diciembre de 1964. Fondo Secretaría de Gobierno. Sección Gobernación. Serie Chinicuila. Caja 1, exp. 15. AGHPEM, Morelia, México.

${ }^{64}$ Secretario general de la Delegación de Inspección Escolar Federal a gobernador. 30 de junio de 1965. Fondo Secretaría de Gobierno. Sección Gobernación. Serie Chinicuila. Caja 1, exp. 15. Aghpem, Morelia, México.

${ }^{65}$ Higinio Ramírez Tolentino a teniente de Caballería de la $21^{\text {a }}$ zona militar. 26 de abril de 1979. Fondo Secretaría de Gobierno. Sección Gobernación. Serie Aquila. Caja 5, exp. s/n. Aghpem, Morelia, México. Gutiérrez (2014, pp. 297-298) ha analizado la función de las fiestas en la región y ha encontrado que por décadas se han suscitado "muchos incidentes violentos", especialmente en las fiestas más grandes, como eran la del Santo Niño Milagroso y la de La Jamaica. La fiesta permitía "ciertas licencias e inversiones de la estructura social", lo que concedía a mujeres y hombres algunas liviandades. El baile se prestaba como un espacio propicio "para las pasiones, para el arrebato, las bravatas, las insinuaciones y los de repentes". No era raro que "salieran a relucir pistolas y machetes".

\section{()(1) $(9$}


mar sus alimentos", pocas veces bajan al pueblo y cuando lo hacen vienen "bien pertrechados". ${ }^{66}$

Un militar, el doctor César Juan López Caballero, que estuvo junto al general Salvador Rangel en el batallón 49, recordaba que en Michoacán "en esa época nadie se dejaba quitar la pistola”. Por eso hubo muchos soldados caídos y varios heridos. Había gente con pistolas que costaban 4000 pesos cuando el sueldo de un médico era de 1200 pesos al mes. Ir contra la cultura de la pistola que viene desde la infancia era muy arriesgado, "hubo personas que en un juego de póker se mataban por veiticinco centavos; era el capricho de querer ganar a la fuerza" ${ }^{67}$

Rangel reconoció que durante la campaña del batallón 49 en el suroeste michoacano hubo 56 miembros de sus tropas que fueron asesinados. Muchos de ellos a causa de la cruzada de despistolización (Veledíaz, 2012, p. 1943). Por ejemplo, en el boletín Tres Palabras número 11 de 1962 refería el caso concreto de dos soldados que fueron muertos en Piedras Blancas sobre el camino de Tepalcatepec. “¿La causa? Todos la conocemos: el desarme sin tomar las más elementales medidas de seguridad [...]. Vieron a un tipo que estaba armado en la parada de los camiones [... y] se le aproximaron para preguntarle si tenía permiso y cuando intentaron usar sus armas, les había ganado la mano el civil, quedando muertos en el acto." Rangel no dejaba de recordarle a sus tropas que extremaran las medidas de seguridad al ejecutar el desarme para evitar mayores bajas: "sólo debe realizarse dentro de poblados o con tipos que lo ameriten fuera de los poblados y en todos los casos, debe ser considerado una operación delicada en la que la menor falla, se traduce en la muerte de quien intenta hacer el desarme". ${ }^{68}$

Dentro de ranchos, caseríos o poblados, afirmaba Rangel, nadie fuera de los policías y encargados del orden debe portar pistola, pero "fuera, en los caminos, por las veredas y en general, en el campo, con o sin autorización todo mundo puede traer un arma para su propia defensa”. Sin embargo, el desarme "de los escandalosos dentro y fuera de poblados continuaremos haciéndolo nosotros con excepción de bailes, cantinas y centros de vicio",

${ }^{66}$ Presidente municipal de Coalcomán a gobernador. 27 de agosto de 1981. Fondo Secretaría de Gobierno. Sección gobernación. Serie Coalcomán. Caja 5, exp. 4. AGHPEM, Morelia, México.

${ }^{67}$ Citado en Veledíaz (2012, pp. 2491 y 2501).

${ }^{68}$ Fondo Secretaría de Gobierno. Sección Gobernación. Serie Apatzingán. Caja 2, exp. s/n. AGHPEM, Morelia, México.

\section{()(1) $\circledast$}


lugares que corresponden a la policía municipal, a menos que esta resulte incompetente y solicite auxilio al ejército. ${ }^{69}$

Si bien dentro de los poblados no se debería portar pistola y sólo se autorizaba en los caminos "y en el campo" (en las fincas o lugares de trabajo), lo cierto es que como ilustran los testimonios arriba referidos, la población masculina adulta se las ingeniaba para llevar armas consigo. Sentían que era el modo de defender sus propiedades, su vida y su honor. Actitudes que por largo tiempo habían estado arraigadas en sus habitus.

\section{CONSIDERACIONES FINALES}

El fenómeno de la violencia en el distrito de Coalcomán es complejo y tiene una larga presencia en la región. Empero, extrañamente aún no ha llamado mucho la atención de los estudiosos. Como el presente artículo ha pretendido mostrar, desde la década de 1940 es posible detectar varias olas de violencia que, con sus diferentes ritmos y temporalidades, se entrelazan entre sí. Una motivada por cuestiones agrarias, que envuelve en una espiral de violencia a pueblos mestizos y comunidades indígenas, pero que también se hace presente en conflictos intercomunitarios. La ocasionada por numerosas gavillas de bandoleros que asolan a diferentes poblados, saqueando casas, negocios, ranchos o robo de ganado; pero que también acuden al secuestro y la extorsión. La ligada a la siembra de enervantes, en la que en no pocas ocasiones se puede apreciar la complicidad de autoridades locales, agentes del Ministerio Público, judiciales y militares. A estas tres formas de violencia, que aquí he denominado instrumentales (dado que hay un cálculo racional en el que se aspira a lograr un bien tangible: tierra, botín, una ganancia monetaria), debe sumársele una violencia ritual ligada al habitus, a la cultura del pistolerismo y a las vendettas que asolaban al distrito en el periodo que aquí se ha explorado.

Todas las anteriores formas de violencia estuvieron profundamente interrelacionadas y afectaron la vida cotidiana de la población michoacana: misma que no dejó de sentirse atemorizada e insegura, pues cada una de ellas atentaba contra sus bienes y su propia vida o la de sus seres queridos. Por ello, junto con unas autoridades municipales claramente rebasadas por el flagelo

${ }^{69}$ Boletín Tres Palabras, núm. 8, 1963. Fondo Secretaría de Gobierno. Sección Gobernación. Serie Apatzingán. Caja 3, exp. s/n. Aghpem, Morelia, México.

\section{()(1) $(9$}


de la violencia, con frecuencia dirigen cartas a las autoridades estatales y federales solicitando partidas militares o, al menos, grupos de judiciales. No obstante, saben que las partidas militares no bastan y que su presencia en los poblados tiende a ser efímera, pues no alcanzan a cubrir al mismo tiempo un territorio tan vasto y difícil de transitar. De ahí que la población se aferre a portar armas y a una cultura de la autodefensa. Es decir, hay un círculo vicioso que conecta a los diversos tipos de violencia. Círculo que era muy difícil de eliminar mientras persistiera una acusada debilidad infraestructural del Estado. De ahí que no sea fortuita la emergencia de grupos de autodefensa en febrero de 2013 para enfrentar a grupos criminales más poderosos (Guerra, 2015b), pues esa debilidad estatal seguía persistiendo en pleno siglo xxI.

Si bien el Estado se valió de diferentes instrumentos para tratar de encapsular las olas de violencia de manera institucional (dotaciones agrarias, comisiones de mediación que recorrían la región promoviendo pactos de no agresión, envío de partidas militares o agentes judiciales), a principios de la década de 1980, todos sus esfuerzos parecían haber sido insuficientes. El agudizamiento de la crisis económica en la que entraría el país a partir de los años ochenta, así como una mayor fuerza adquirida por la delincuencia organizada, en especial de los cárteles del tráfico de enervantes, parecen haber hallado un buen caldo de cultivo en el distrito de Coalcomán para que la violencia siguiera permeando las interacciones sociales en la región. ${ }^{70}$

Muchos de estos aspectos se relacionan con un Estado que históricamente ha tenido fuertes limitaciones para penetrar en términos infraestructurales en el suroeste michoacano y hacerse del monopolio legítimo de la violencia, garantizando servicios adecuados a la ciudadanía: especialmente, los del imperio del Estado de derecho y brindar seguridad pública a la ciudadanía.

\section{LISTA DE REFERENCIAS}

Alarcón, A. (1998). Pómaro: identidad y cambio social. (Tesis de maestría). El Colegio de Michoacán, Zamora.

Anda, M. de (1977). Informe relativo a la exploración del distrito de Coalcomán. Presentado al Sr. Ministro de Fomento. Anuario, 2, 165-234.

70 Sobre el ascenso de nuevos cárteles, véase Grillo (2016).

\section{()(1) $(9$}


Aróstegui, J. (1994). Violencia, sociedad y política: La definición de la violencia. Ayer, 13, 17-55. Recuperado de http://www.jstor.org/stable/41324344

Arreola. R. (1980). Coalcomán. Monografías municipales del estado de Michoacán. Morelia: Gobierno del Estado.

Arteaga, N. (mayo-agosto, 2003). El espacio de la violencia: un modelo de interpretación social. Sociológica, 52, 119-145. Recuperado de http://www.sociologicamexico. azc.uam.mx/index.php/Sociologica/article/view/386

Barret, E. (1975). La cuenca del Tepalcatepec. II. Su desarrollo económico. México: SEP (SepSetentas).

Bourdieu, P. (2000). Elementos para una sociología del campo jurídico. En P. Bourdieu y G. Teubner. La fuerza del derecho (pp. 153-220). Bogotá: Siglo del Hombre Editores/Facultad de Derecho-Universidad de los Andes.

Bourdieu, P. y Wacquant, L. (2008). El propósito de la sociología reflexiva (seminario de Chicago). En P. Bourdieu y L. Wacquant, Una invitación a la sociología reflexiva (pp. 91-266). Buenos Aires: Siglo XXI.

Brand, D. (1958). Coalcoman and Motines de Oro, an exdistrito of Michoacan, Mexico. Austin: The University of Texas.

Brand, D. (2013). Estudio costero del suroccidente de México. Morelia: unAm.

Calderón, M. (2001). Lázaro Cárdenas del Río en la cuenca de Tepalcatepec-Balsas. En J. E. Zárate (coord.). La tierra caliente de Michoacán (pp. 233-266). Zamora: El Colegio de Michoacán/Gobierno del Estado de Michoacán.

Cochet, H. (1991). Alambradas en la sierra. Un sistema agrario en México. La sierra de Coalcomán. México: El Colegio de Michoacán.

Crettiez, X. (2009). Las formas de la violencia. Buenos Aires: Waldhuter.

Collins, R. (2009). Violence: A Micro-sociological Theory. Princeton: University Press.

Das, V. y Poole, D. (2008). El estado y sus márgenes. Etnografías comparadas. Cuadernos de Antropología Social, 27, 19-52. Buenos Aires: Universidad de Buenos Aires. Recuperado de http://www.scielo.org.ar/pdf/cas/n27/n27a02.pdf

Elias, N. (1999). Los alemanes. México: Instituto Mora.

Figueroa D. (agosto, 2008). Conflicto social, tradición e identidad étnica en la costa nahua de Michoacán. Espacios Públicos, 11(22), 353-366. Recuperado de http:// www.redalyc.org/articulo.oa?id=67602220

Gledhill, J. (2004). Cultura y desafío en Ostula. Zamora: El Colegio de Michoacán.

González, A. (junio, 1966). Problems of agricultural development in a pioneer region of sothwestern coastal Mexico. Revista Geográfica, 64, 29-52.

\section{()(1) $(9$}


González, L. (2001). Introducción: la tierra caliente. En J. E. Zárate (coord.). La tierra caliente de Michoacán (pp. 17-66). Zamora: El Colegio de Michoacán/Gobierno del Estado de Michoacán.

Grillo, I. (2016). Caudillos del crimen. México: Grijalbo (edición para Kindle).

Guerra, E. (enero-junio, 2013). Civilización y violencia en la obra de Norbert Elias. Iztapalapa. Revista de Ciencias Sociales y Humanidades, 74, 129-154. Recuperado de http://revistaiztapalapa.izt.uam.mx/index.php/izt/article/view/94

Guerra, E. (2015a). Del fuego sagrado a la acción cívica: los católicos frente al Estado en Michoacán, 1920-1940. México: El Colegio de Michoacán/Ítaca/Universidad Autónoma Metropolitana-Xochimilco.

Guerra, E. (otoño, 2015b). Las autodefensas de Michoacán: movimiento social, paramilitarismo y neocaciquismo. Política y Cultura, 44, 7-31.

Gutiérrez, D. (verano de 2014). Por el camino real de la costa. Apuntes sobre la tradición mariachera en la costa de Michoacán. Relaciones, 139, 281-304. DOI: http:// dx.doi.org/10.24901/rehs.v35i139.141

Guzmán, A. (1990). Sociología y violencia. Cali: Universidad del Valle/fcsye.

Heyman, J. y Smart, A. (1999). States an illegal practices: An overview. En J. Heyman (ed.), States an Illegal Practices (pp. 1-24). Oxford: Berg.

Maldonado, S. (2010). Los márgenes del Estado mexicano. Territorios ilegales, desarrollo y violencia en Michoacán. Zamora: El Colegio de Michoacán.

Mann, M. (julio-setiembre, 2004). La crisis del Estado-nación en América Latina. Desarrollo Económico. Revista de Ciencias Sociales, 44(174), 179-198. Dor: http://dx.doi. org/10.2307/3456035

Marín, G. (noviembre, 2007). Pesca artesanal, comunidad y administración de recursos pesqueros. Experiencias en la costa de Michoacán, México. Gazeta de Antropología, 23, 1-16. Recuperado de http://www.ugr.es/ pwlac/G23_20Gustavo_Marin_Guardado.html

Medrano, G. (julio-diciembre, 2004). Entre la sierra y el mar. Algunas artesanías de la costa nahua de Michoacán. Tzintzun, 40, 135-160.

Meyer, J. (1993). La cristiada, vol. III. México: Siglo XXI.

Monroy, S. (2006). Nahuas de la costa-sierra de Michoacán. México: Comisión Nacional para el Desarrollo de los Pueblos Indígenas.

Mora, A. (2011). La institución comunitaria y el aprovechamiento de recursos forestales en una comunidad indígena nahua de la costa de Michoacán. (Tesis de licenciatura). CIEUNAM. Morelia, México.

Muchembled, R. (2010). Una historia de la violencia. Del final de la Edad Media a la actualidad. Madrid: Paidós.

\section{()(1) $(9$}


Núñez, R. (2011). Hacia un análisis histórico de la migración en la comunidad de la Cofradía de Ostula, Michoacán. CIMEXUS. Revista de Investigaciones México-Estados Unidos, 6(1), 179-196. Recuperado de http://cimexus.umich.mx/index.php/ cim1/article/view/97/89

Ochoa, A. (1990). La violencia en Michoacán. Ahí viene Chávez García. Morelia: Instituto Michoacano de Cultura.

Purnell, J. (1999). Popular movements and state formation in revolutionary Mexico. The agraristas and cristeros of Michoacán. Durham: Duke University Press.

Reinberg, N. (2007). Retos y memorias. Encuentro con la globalización y el mundo de la gente de El Faro de Bucerías-localidad perteneciente a la comunidad de El Coire en la costa-sierra de Michoacán. Viena: University of Viena.

Sánchez, G. y Carreño, G. (1979). El movimiento cristero en el distrito de Coalcomán, Michoacán, 1927-1929. Boletín del Centro de Estudios de la Revolución Mexicana Lázaro Cárdenas, II(2), 99-121.

Spierenburg, P. (2008). A history of murder. Personal violence in Europe from the middle ages to the present. Cambridge: Polity Press (edición para Kindle).

Topete, H. (2017). La costa-sierra nahua michoacana, entre el oleaje del mar, la agricultura, el turismo y el narcotráfico. Batey: Revista Cubana de Antropología Sociocultural, 9(9), 77-83. Recuperado de https://dialnet.unirioja.es/servlet/ articulo?codigo $=5825816$

Veledíaz, J. (2012). El general sin memoria. Una crónica de los silencios del ejército mexicano. México: Debate (edición para Kindle).

\section{OTRAS FUENTES}

Aghpem Archivo General e Histórico del Poder Ejecutivo de Michoacán, Morelia, México.

AGN Archivo General de la Nación. 